\title{
Surgical treatment in deep digital sepsis in cattle - Claw preserving methods and claw amputation
}

Johann Kofler

Associate Professor, Dr., DECBHM, Department of Farm Animals and Veterinary Public Health, University Clinic for Ruminants, University of Veterinary Medicine Vienna (VUW), Vienna, Austria

e-mail: Johann.Kofler@vetmeduni.ac.at

\section{Introduction}

Still today lameness represents a major health problem in many dairy farms with prevalences ranging from 0 to $70 \%$; mean prevalence rates of about 36\% were reported by many authors (Clarkson et al., 1996; Green et al., 2002; RouhaMülleder et al., 2009; Olechnowicz \& Jaskowski, 2010). Unfortunately, the lameness prevalence is highly underestimated by farmers (Sárová et al., 2011). An acceptable lameness prevalence in dairy herds regarding ethical and economical considerations is $5 \%$ to maximal $10 \%$ (EFSA, 2009). Lameness continues to be one of the largest economic drains on dairy farming and is one of the three most common reason for culling, preceded by reproductive failure and mastitis (Enting et al., 1997; Whitaker et al., 2000; Warnick et al., 2001; Green et al., 2002; Hernandez et al., 2002; Booth et al., 2004; Van Amstel \& Shearer, 2006; Barker et al., 2009; Olechnowicz \& Jaskowski, 2011). Lameness results in direct loss via culling as well as indirect loss via decreased production of milk, milk fat and protein, reproductive failure, prolonged calving interval, extra labor of the dairy farmer and the foot trimmer, extra visits of the veterinarian, treatment costs and costs for discarded milk (Enting et al., 1997; Whitaker et al., 2000; Hernandez et al., 2001, 2002; Green et al., 2002; Booth et al., 2004; Wangler et al., 2006). The total costs for a lame cow per year were estimated with 450 \$ (Greenough et al., 1997). The costs for a sole ulcer were calculated with a loss of \$ 216 per case, for digital dermatitis with \$ 132 per case and for foot rot with $\$ 120$ per case (Cha et al., 2010). Average costs of about $\$ 4,899$ per year (ranging from $\$ 3,217$ to $\$ 7,001$ ) were calculated in a Dutch study (Bruijnis et al., 2010) due to foot disorders for a single farm with 65 cows. The costs of subclinical foot disorders were estimated with $32 \%$ of all costs (Bruijnis et al., 2010).

About $90 \%$ of all limb disorders in cattle result from claw diseases, independent of breed, use or 
housing (Barkema et al., 1994; Clarkson et al., 1996; Hernandez et al., 2002). Lameness is often chronic, causes pain (Green et al., 2002; Van Amstel \& Shearer, 2006) and is an im-portant welfare concern (O'Callaghan, 2002; Huxley \& Whay, 2006; Shearer et al., 2013).

Claw disorders associated with chronic laminitis and environmental factors originating from inadequate flooring and inadequate bedding areas are primary causes of lameness in most herds. These factors are complicated by stress (overcrowding, heat), poor hygiene and other poor management considerations (Nocek, 1997; Barker et al., 2009; Rouha-Mülleder et al., 2009; Cook \& Nordlund, 2010). Infectious skin disorders of the foot include digital dermatitis and interdigital phlegmon (Bergsten et al., 1997; Döpfer et al., 2012).

Regardless of the cause of claw disorders, early detection and prompt treatment minimizes losses, improves outcome, and reduces animal suffering. Treatment of superficial claw disorders such as sole ulcers, toe ulcers, white line lesions, and interdigital phlegmon is often delayed, inappropriate or not provided atall because the problem is not recognised by owners and veterinarians without specific expertise and training in this field $\left(\mathrm{O}^{\prime}\right.$ Callaghan, 2002; Huxley \& Whay, 2006; Kofler, 2014).

The consequence of delayed or inappropriate treatment of these superficial claw disorders, often involving the corium only, is the development of deep digital sepsis associated with severe lameness scores. The circumscribed purulent processes of the claw corium spreads to deeper structures involving subsequently the deep digital flexor tendon (DDFT) at their insertion site at the pedal bone, the podotrochlear bursa, the distal sesamoidal bone, the pedal bone (flexor tubercle) and results finally in an infection of the distal interphalangeal joint (DIJ) and/or the digital flexor tendon sheath (DFTS) (Köstlin \& Nuss, 1988; Kofler \& Fessl, 1989; Weaver, 1991; Desrochers et al., 2008; Heppelmann et al., 2009a). Penetrating injuries and haematogenous spread of infection are other less common causes for deep digital sepsis (Heppelmann et al., 2009a). In the majority of cases with infection of the DIJ, other adjacent anatomical structures are involved, including the deep digital flexor tendon, the podotrochlear bursa and the flexor tendon sheath, in addition to the distal sesamoid bone and the middle (P2) and distal phalanges (P3), which form the joint (Kasari et al., 1987; Kofler \& Fessl, 1989; Weaver, 1991; Nuss, 2004; Desrochers et al., 2008; Heppelmann et al., 2009a).

Conservative treatment of deep digital sepsis, which may involve functional claw trimming, paring off and reducing the pressure on the defect and administration of antibiotics and nonsteroidal anti-inflammatory drugs, is not usually rewarding and only prolongs the patient's discomfort (Breuer, 1963; Baxter et al., 1991; Ferguson, 1997; O'Callaghan, 2002; Desrochers et al., 2008; Heppelmann et al., 2009a). The only economically viable and promising treatment option, if euthanasia or slaughter is not undertaken, is radical surgical resection of all the infected tissues, which often cannot be reached anymore by the systemic antibiotic due to failure of perfusion (Greenough \& Ferguson, 1985; Baxter et al., 1991; Desrochers \& St Jean, 1996; Ferguson, 1997; Nuss, 2004; Heppelmann et al., 2009a).

Surgical treatment of deep digital sepsis may involve on the one hand claw preserving surgery, which include joint lavage, arthrotomy, resection of the distal sesamoid bone, resection of DIJ, amputation of the tip of the pedal bone and on the other hand the amputation of the complete claw or the distal digit using various methods (Kofler \& Fessl, 1989; Baxter et al., 1991; Nuss \& Weaver, 1991; Pejsa et al., 1993; Nuss, 2004; Bicalho et al., 2006, 2007; Kofler et al., 2007; Starke et al., 2007; Desrochers et al., 2008; Heppelmann et al., 2009a).

The aim of surgical treatment is to resolve lameness and pain rapidly and to restore production using surgical methods that can be applied easily by every veterinarian with some training in this field, and that involve a reasonable amount of aftercare for the practical veterinarian. The invasiveness of the surgical treatment method selected depends on the type of lesion, the extent of involvement of anatomical structures and the diagnostic options for their precise recognition in practice, the economic feasibility and the practicality of the surgery (Heppelmann et al., 2009a).

In the following abstract, surgical techniques and their indications for treatment of deep digital sepsis including infection of the pedal bone, the 
DIJ and DFTS in cattle are presented. In addition, multimodal regimes for management of the surgically treated patient regarding the peri- and post-operative pain management and antibiosis are described.

\section{Physical examination of the claw and diagnostic procedures}

To facilitate the examination of the claw, the cow and their limbs should be restraint on a claw trimming table in lateral recumbency or in a walkin-claw-trimming crush where the affected limb is lifted. The surface of the sole should be washed and in most cases a functional claw trimming is indicated. In any case, it can be helpful to cut off a thin layer of superficial horn together with the caked material to expose fresh horn beneath. This allows a good visual examination of the sole horn and the white line zone. Now the surface has to be examined carefully for horn defects, separations of the white line, black marks, and by exploring them with a probe.

Particular attention should be paid to the abaxial white line area. Removal of large amounts of sole horn is contraindicated in the diagnostic phase of an examination. The sole and wall can be examined for painful reactions using a hoof tester. The interdigital space is evaluated by separating the claws and looking carefully for evidence of an interdigital hyperplasia, foot rot, digital dermatitis, or wounds. Furthermore the periople, the coronet and the bulbs of the heels have to be examined for the presence of inflammatory signs such as slight or severe swelling, reddening, discharge of exudate, the presence of fistulas and pain (Kofler 2014).

The presence of moderate to severe swelling of these areas is always indicative for a deep digital sepsis involving the pedal bone, the distal sesamoidal bone, the deep digital flexor tendon and the distal interphalangeal joint. The presence of an overextended claw in combination with a sole ulcer, white line disease or an interdigital phlegmon is indicative for a necrosis of the DDFT at its insertion site (Starke et al., 2008; Heppelmann et al., 2009a; Kofler, 2014).
To verify deep digital sepsis in practice, the veterinarian can use a probe for exploring lesions: depending on the length and the direction where the probe can be inserted the verification of the involvement of deep bony structures, the DIJ or the DFTS is simple. In addition for verification of a suspected septic arthritis or tenosynovitis of the DFTS a puncture of these synovial pouches can be carried out using a cannula of about $2 \mathrm{~mm}$ diameter, followed by the macroscopic evaluation of the effusion. A turbid effusion is always indicative for a septic process (Rhode et al., 2000; Starke et al., 2008; Kofler 2014).

Another diagnostic technique, which can be applied today in practice for making a definite diagnosis in bovine limb disorders is diagnostic ultrasound. This imaging modality can be applied anywhere in bovine practice and allows a rapid non-invasive differentiation of swollen soft tissue structures of the bovine limbs. Ultrasound units with 5.0 to $7.5 \mathrm{MHz}$ linear transducers (rectal probes), commonly used in large animal reproduction, are well suited for rapid and straightforward differentiation of soft tissue swelling in the limbs too (Heppelmann et al., 2009b; Kofler, 1996a,b, 2009, 2011; Kofler et al., 2014). Ultrasonography provides accurate information about the location and size of lesions or fluid-filled cavities (joint pouches, tendon sheaths, bursae), the surrounding tissues and the nature of the content, and enables a targeted puncture.

The physiological amount of synovial fluid of normal synovial cavities in cattle cannot be imaged by ultrasound. Visualization of effusion is easy and usually indicates an inflammatory process. Therefore, ultrasonography can detect early stages of inflammation of synovial cavities based on an increased amount of effusion and distension of the synovial pouch. An early diagnosis, accurate anatomical differentiation of the soft tissue structures involved, characterization of the lesions and a thorough preoperative inspection of incriminated regions are of enormous benefit for determining an accurate prognosis as well as planning surgery and treatment (Kofler \& Edinger, 1995; Kofler, 1996a,b; Heppelmann et al., 2009b; Kofler, 2009; Kofler et al., 2014). 

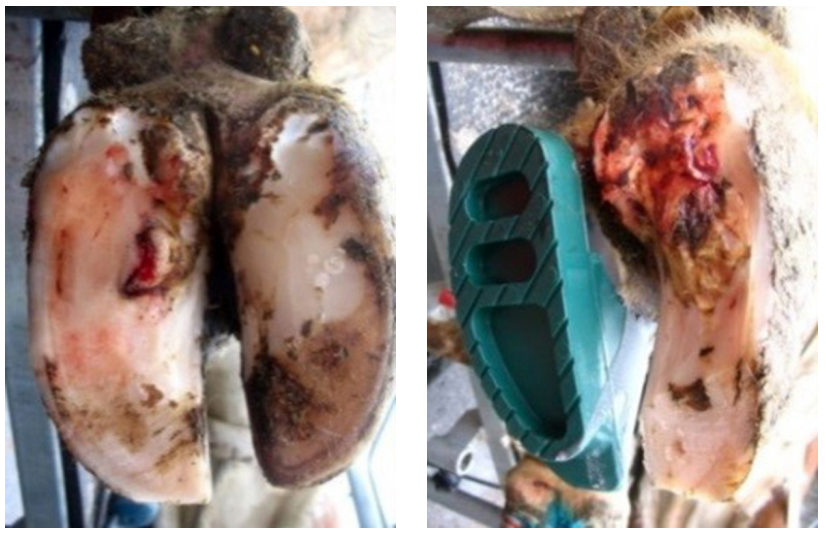

Typical sole ulcers at the axial border of the sole (small and a large sole ulcer). In these cases the infection involves the corium only, there is no swelling at all at the bulbs of the heel and at the coronet.
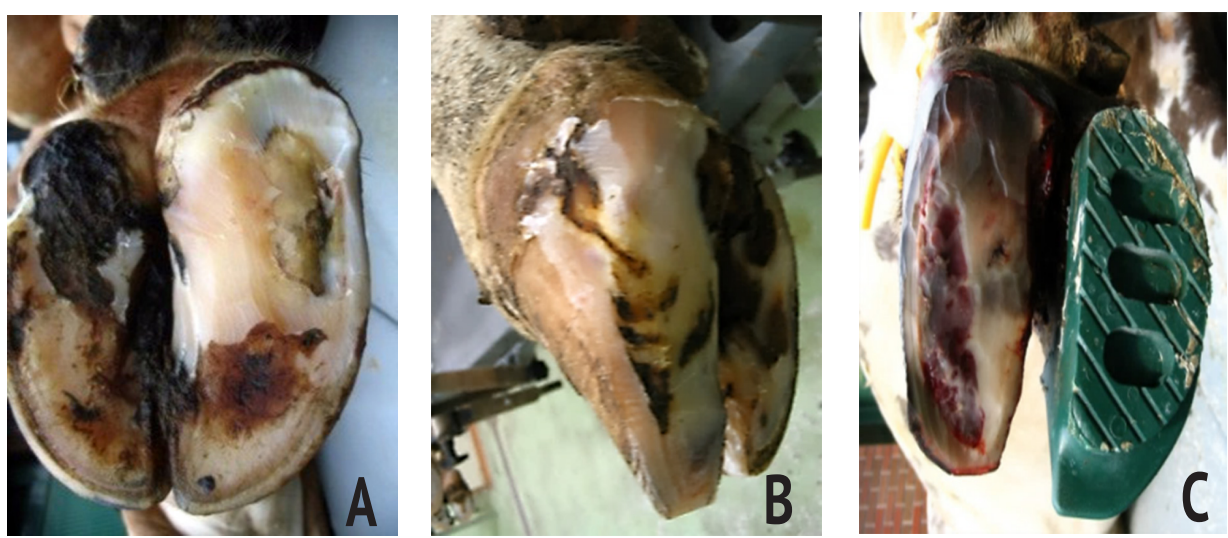

Various examples of white line lesions (A, B) and of a white line infection (C) with discharge of purulent exudate and the adequate treatment (trimming, blocking). Again, in these cases the infection involves the corium only, there is no swelling at all at the bulbs of the heel and at the coronet.
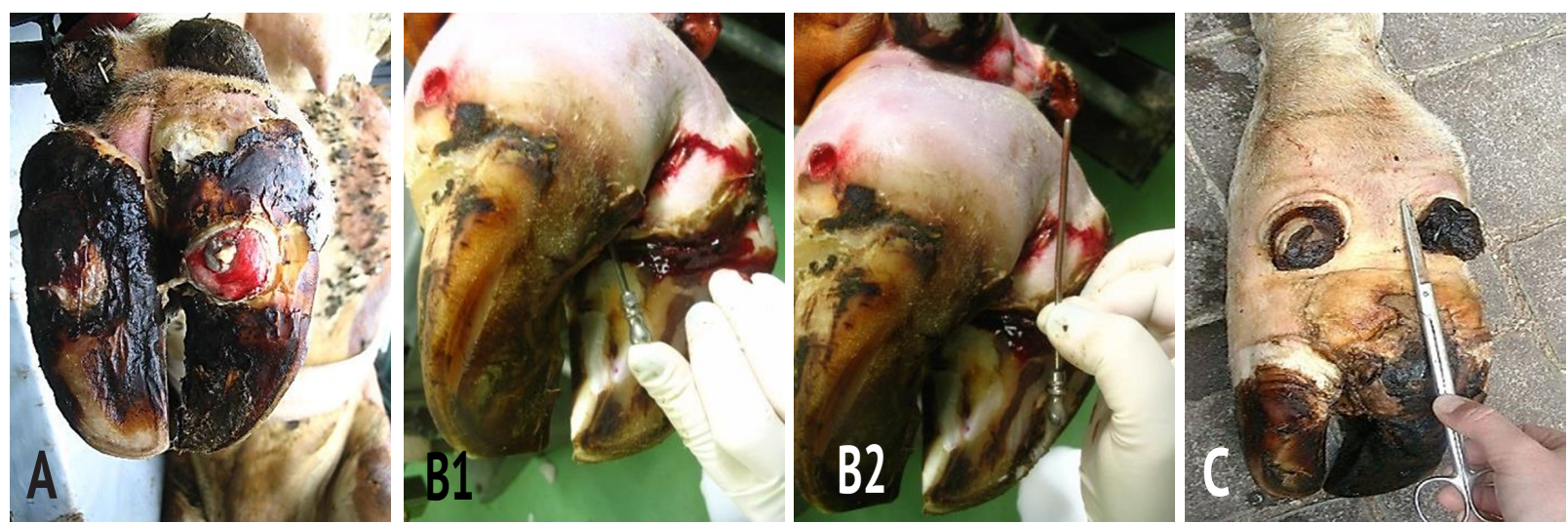

Various examples of claws with sole ulcers and an associated large swelling of the bulbs of the heels (A, B1, B2) and a typical extent of swelling in a case of purulent infection of the digital flexor tendon sheath (C). Already the clear visible swelling indicates a deep digital sepsis. Using a probe (B1, B2, C) the length of the extent of the deep digital infection can be explored and regarding the location of the tip of the probe it is clear which structures are involved; the DIJ in Figures B1 and B2, and the digital flexor tendon sheath in Figure $\mathrm{C}$. 

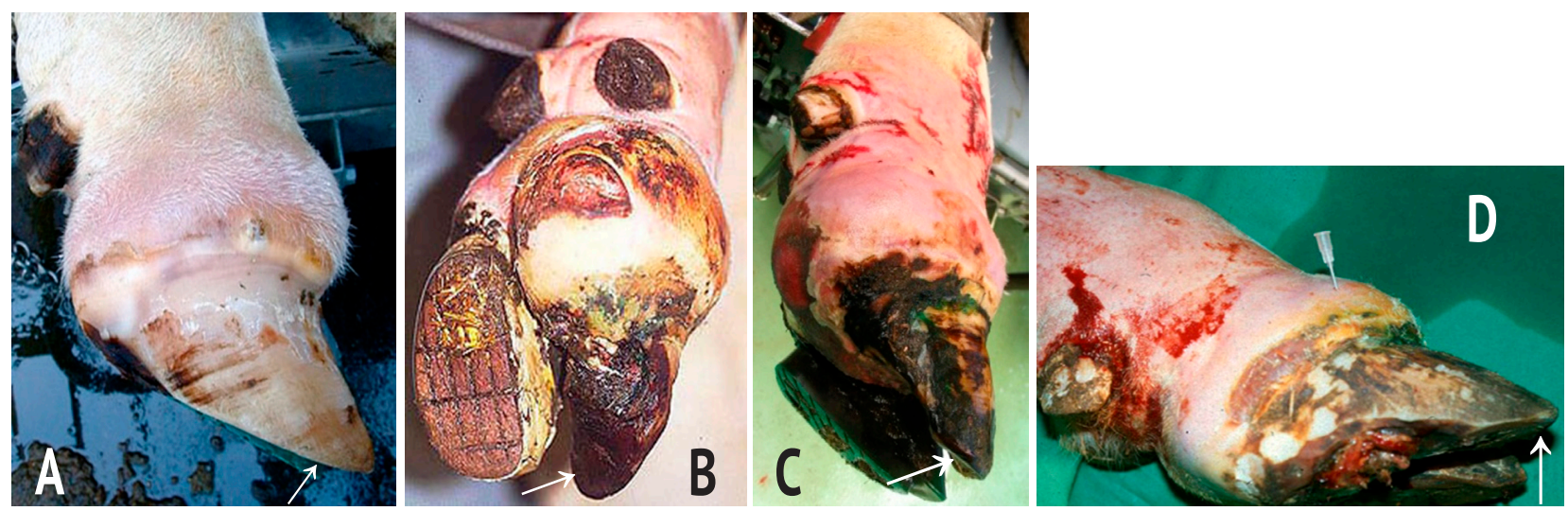

Various of claws showing a purulent arthritis of the distal interphalangeal joint originating from white line disease $(A, B, C)$ and sole ulcers (D) by showing the typical circular swelling at the coronet the bulbs of the heels (A-D). In addition in all the four examples a hyperextension (arrows) of the affected claw can be detected, indicating clearly an infection and necrosis of the insertion site of the deep digital flexor tendon. Figure D shows the primary sole ulcer, the typical hyperextended lateral claw, the typical circular swelling at the coronet form dorsal to plantar. An arthrocentesis was carried out to confirm the suspected septic arthritis by insertion of the cannula into the dorsal joint pouch.

\section{Deep digital sepsis - Surgical procedures and indications}

\section{Interdigital phlegmon \\ (Interdigital necrobacillosis, Foot rot)}

Interdigital phlegmon is an infectious claw disease of cattle characterized by the rapid development of a necrotic lesion in the interdigital skin. Due to lesions or weakening of the skin at the interdigital space, specific bacteria (Fusobacterium necrophorum, Porphyromonas levii, Dichelobacters nodosus) may enter and infect the subcutaneous tissue. Infected animals are suddenly severely lame and a distinct swelling in and above the interdigital space develops within some hours (Bergsten et al., 1997; Reinöhl-DeSouza \& Kofler, 2006).

Prompt treatment in the early stage is crucial to success and to avoid complications. Treatment of interdigital phlegmon generally requires systemic antibiosis given for 3-5 days. The antibiotic drug of choice is cephalosporine (Ceftiofur sodium) due to the short or due to no withdrawal time for milk, however other drugs (amoxicillin, penicillin, tetracycline) are reported to be also effective (Morck et al., 1998; Nuss, 2004). The simultaneous treatment of the interdigital lesion by careful washing and cleaning is recommended to improve the outcome. Various antiseptic solutions or oxytetracyclin spray may be used topically, and bandaging of the foot is optional (Reinöhl-DeSouza \& Kofler, 2006).

However, it has to be stressed out that in advanced cases of interdigital phlegmon or when there is no improvement of 4 days of systemic antibiotis the treatment of choice is surgery by careful removal of all infected interdigital tissue under intravenous regional anesthesia (Nuss, 2004; Reinöhl-DeSouza \& Kofler, 2006), lavage of the wound, topical application of oxytetracyclin spray and a bandage. 

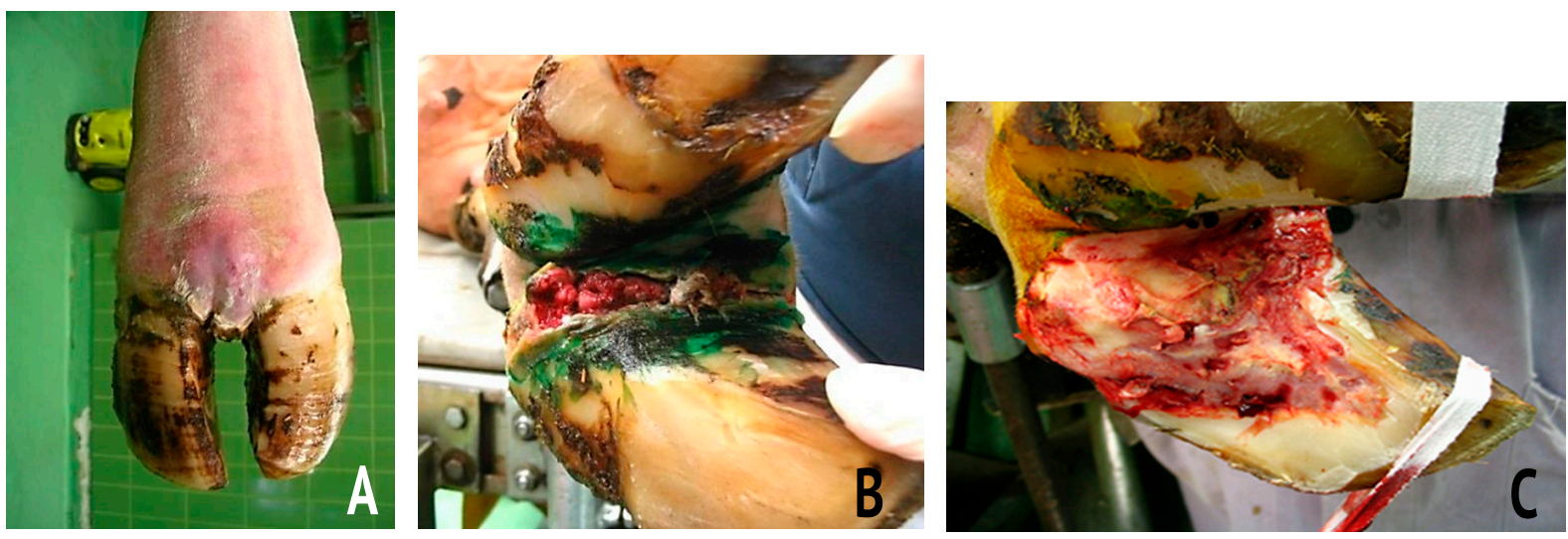

Typical appearance of an interdigital phlegmon with distinct swelling of the interdigital area, the coronet and with erythema of the dorsal skin (A). The interdigital view (B) shows the skin fissure, necrotic brown-colored tissue and granulation tissue indicating an older process. In addition, the proximal part of the axial wall horn is frequently separated from the corium (arrow) due to the infection. In this advanced case, all the necrotic tissue, all the undermined parts of the axial wall horn and the undermined sole horn were removed carefully, a tissue zone showing discoloration (yellow-brown) is still visible (circle) and has to be resected (C). To avoid weightbearing of this highly painful lateral claw during the $4-6$ weeks post-surgery, a block has to be attached at the sound partner claw.

\section{Joint lavage and arthrotomy}

The aim of joint lavage and arthrotomy of the distal interphalangeal joint (DIJ) is to preserve the morphology and function of the infected joint. Joint lavage is performed in cases of acute septic arthritis of the DIJ showing a serous or serofibrinous effusion (early stages of a septic arthritis). A needle should be inserted about $1 \mathrm{~cm}$ dorso-proximal to the coronary band, axial or abaxial to the common extensor tendon, and at an angle of $60 \mathrm{o}$ to the coronary band. A second needle is then placed plantar/palmar to the abaxial collateral ligament at an angle of 450 . The joint should be lavaged with 1 L of $0.9 \%$ isotonic saline solution (Desrochers \& StJean, 1996; Meier, 1997; Reinöhl-DeSouza \& Kofler, 2006; Kofler et al., 2007; Desrochers et al., 2008) or with $0.1 \%$ povidone-iodine solution in $0.9 \%$ isotonic saline solution (Baxter et al., 1991; Kofler \& Martinek, 2005; Heppelmann et al., 2009a) until the flushed fluid remains clear and without fibrin clots.

Following joint lavage, antibiotics, such as ceftiofur or penicillin $G$, can be injected into the joint. Joint lavage should be performed over at least three consecutive days, after which it may be continued or discontinued depending on the degree of clinical improvement and findings of repeated macroscopic evaluation and/or cytology of synovial fluid samples (Meier, 1997; Kofler \& Martinek, 2005; Reinöhl-DeSouza \& Kofler, 2006; Kofler et al., 2007; Desrochers et al., 2008; Heppelmann et al., 2009a). In addition, antibiotic administration may also be indicated.

Arthrotomy should be undertaken in joints with high synovial clotted fibrin content, with arthritis attributable to a puncture wound or with deep secondary infection, such as interdigital phlegmon (necrobacillosis) (Reinöhl-DeSouza \& Kofler, 2006; Starke et al., 2008; Heppelmann et al., 2009a). The joint should be approached from the site of the primary lesion (axial) and all necrotic soft tissue and infected cartilage and bone are removed completely from the wound area using a curette. Joint lavage should be carried and directed out from the inside toward the outside via the wound using a needle placed in the dorsal joint pouch.

When a perforating wound cannot be found, the joint can be opened at the positions of arthrocentesis (dorsal, abaxial) for removal of abnormal joint effusion. The changes in the joint cartilage, bone and soft tissues advance rapidly so that joint lavage and arthrotomy with local curettage are no longer an 
adequate treatment method. More invasive surgical techniques are required in advanced cases showing a purulent-necrotising arthritis or in patients that showed no clinical improvement within 10 days after surgery (Baxter et al., 1991; Desrochers \& St-Jean, 1996; Pedersen, 2007; Starke et al., 2008; Heppelmann et al., 2009a).

\section{Resection of the tip of the pedal bone}

Toe ulcers frequently causes an infection of the tip of the pedal bone, which can affect the dorsal $1 / 4,1 / 3$, the half or more of the pedal bone. The diagnosis of pedal bone necrosis at the toe can be done easily by physical examination, the corium appears necrotic and often the necrotic and infected bone is exposed and appears with a yellow to greybrown color (Kofler, 1999; Nuss, 2004; Kofler 2017; Kofler et al., 2017). The only adequate treatment is surgical resection or amputation of the infected tip of the pedal bone. After intravenous regional anesthesia, and after blocking the sound partner claw and careful cleaning and disinfection of the affected claw (the complete horn surface), amputation can be carried out using a wire saw (Nuss, 2004) or using angle grinders fitted with a titanium six knife grinding disk (Kofler, 1999; Kofler, 2017; Kofler et al., 2017). This disc can be carefully cleaned and disinfected. Starting from the tip of the claw the horn capsule with the all infected bone is removed with the rotating knife grinding disk till the healthy bone is reached. The wound is lavaged with $0.9 \%$ saline solution, topical antibiotic spray and a bandage is applied. Recently, a high herd prevalence of endemic digital dermatitis (DD) infection exists in a number of countries today, inevitably favoring a secondary infection of toe lesions with exposed corium with DDassociated Treponema spp. (Kofler et al., 2015). If the apical pedal bone is involved in these cases, the same treatment as mentioned above with resection of all infected tissue has to be carried out (Kofler, 2017).
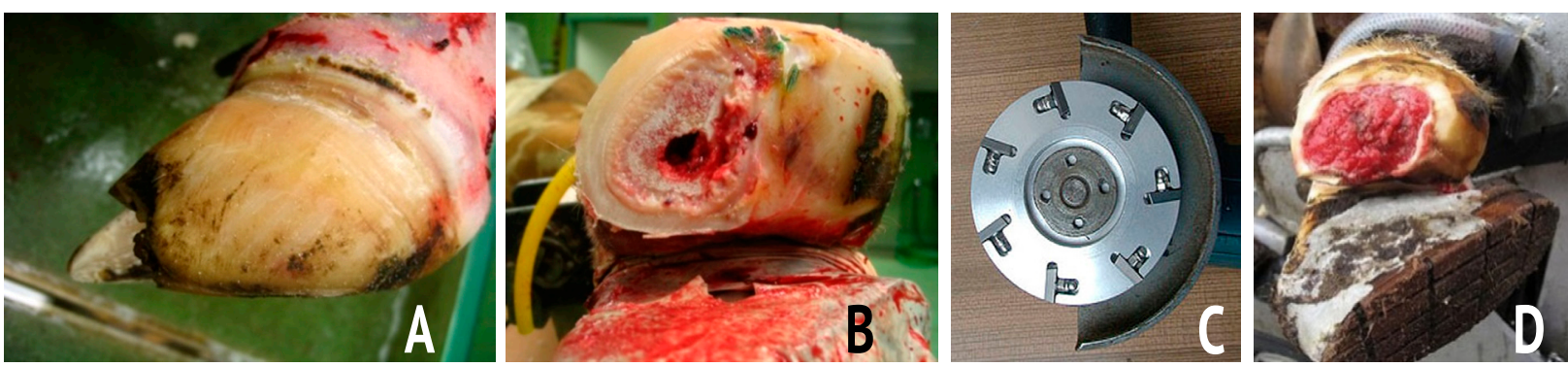

Necrosis of the apex of the phalanx 3 after an open fracture of the tip of the claw (A): the infected part of the bone was amputated (B) using the angle grinder fitted with a titanium six knife grinding disk (C), the healing of this wound is shown in Figure D: status after 14 days, the wound is covered completely by granulation tissue and the healing is proceeded very quickly.

\section{Resection of the distal sesamoid bone}

Resection of the distal sesamoid bone is indicated for complicated sole ulcers and white line disease in the plantar/palmar sole region with perforation of the corium and subsequent purulent or necrotising tendonitis at the level of insertion of the deep digital flexor tendon, purulent podotrochlear bursitis and osteomyelitis of the distal sesamoid bone (Jeong,
1993; Desrochers et al., 1995; Heppelmann et al., 2009a). When the plantar/palmar cartilage of P3 and P2 or the flexor tubercle of P3 are affected, this technique can be expanded and may finally include resection of the involved bone necrosis and curettage of the visible joint surface of the plantar/ palmar aspect of P3 (Jeong, 1993). Septic arthritis of the DIJ can be treated via resection of the distal sesamoid bone providing adequate drainage of the 
joint (Köstlin \& Nuss, 1988; Blikslager et al., 1992; Heppelmann et al., 2009a). A thorough joint lavage is recommended after sesamoid bone resection by placing the needle into the dorsal pouch.

After paring off the horn from the heel and caudal sole region, an incision is made around the defect (sole ulcer, white line disease) in a funnelshaped fashion in the plantar/palmar third of the sole or heel area extending to the insertion site of the deep digital flexor tendon. This tendon should be transected proximal to the infected area, and the insertion of the deep digital flexor tendon, the digital cushion and the podotrochlear bursa are removed. By flexing the claw, tension of the sesamoid ligaments can be lowered to ease their resection and enable an easy removal of the sesamoid bone. The exposed plantar/palmar joint cartilage of the distal part of $\mathrm{P} 2$ is curetted, and the flexor tubercle is then resected with a trephine or hammer and a chisel (Jeong, 1993; Heppelmann et al., 2009a). The wound and joint have to be lavaged via a cannula placed in the dorsal recess. Cartilage, bone and soft tissue changes that extend beyond the plantar/palmar aspect of the DIJ cannot be treated by sesamoid bone resection. This also applies when clotted solid joint content cannot be removed via a plantar/palmar approach. In these cases, more invasive surgery is required (Heppelmann et al., 2009a).

\section{Resection of the distal interphalangeal joint (DIJ)}

Resection of the DIJ is a surgical technique to achieve a ankylosis by extensive removal of septic altered cartilaginous, subchondral and deeper osseous tissues, including a thin layer of healthy bone. The approach for resection of the DIJ may be plantar/palmar, dorsal, abaxial or axial. It depends on the location of the primary disorder (white line disease, sole ulcer, interdigital phlegmon or the location of a perforating wound involving the joint (Desrochers et al., 1995; Desrochers \& St-Jean, 1996; Ferguson, 1997; Heppelmann et al., 2009a) and cannot be chosen at random.

\section{Plantar/palmar approach}

A plantar/palmar approach for resection of the DIJ is most commonly used and is only slightly more labour intensive than the above described method of sesamoid bone resection, but has a broader spectrum of indications. It is used for septic arthritis of the DIJ with subchondral lysis of the bony part of the joint, which results from deep infection of the corium in the plantar/palmar sole and the plantar/ palmar aspect of the claw wall (sole ulcer, white line disease). A plantar/palmar approach is therefore used most frequently. The location of the incision, instrumentation, the number of excised structures and choice of tendon resection vary depending on the surgeon.

The technique was published by Breuer (1963) and Westhues \& Breuer (1964) and has been modified over time by other surgeons. Köstlin \& Nuss (1988), Nuss \& Weaver (1991) and Nuss (2004) described a practical technique of resection of the DIJ for treatment of septic arthritis in detail. A longitudinal skin incision should be made at a point immediately distal to the dew claw and extended distally to the heel, ending in an oval incision around the tract of the penetrating claw defect. Then a piece of horn is then removed, the deep digital flexor tendon is transected, the distal sesamoid bone is removed and necrotic parts of the flexor tubercle are resected. Using a drill with a bit diameter of 8-10 $\mathrm{mm}$, a hole is drilled through the centre of the DIJ emerging at the dorsal claw surface immediately below the coronary band. During drilling the surgery site should be flushed continuously with sterile $0.9 \%$ isotonic saline solution to prevent bone damage due to over-heating. Provided that there are no lesions in these areas, axial and abaxial bony extensions are left in place on P3 and P2. This should prevent luxation of P3 by providing stability for successful ankylosis. Thorough resection of all necrotic soft tissue, cartilage and bone is strictly required for a successful outcome (Trostle et al., 1996; Nuss, 2004; Kofler et al., 2007; Heppelmann et al., 2009a).

Today, the current standard procedure is to drill a hole from the plantar/palmar to the dorsal aspect of the joint using a sterilized wood drill (Köstlin \& Nuss, 1988; Kofler et al., 2007; Starke et al., 2007; Heppelmann et al., 2009a). The drill hole through the DIJ also provides drainage of the dorsal recess and facilitates postoperative lavage. This surgical technique is successful in cases of serofibrinous and mild purulent septic arthritis of the 
DIJ, but only when all of the infected tissue (soft and bone) has been completely removed (Nuss, 2004; Heppelmann et al., 2009a).

If it is suspected that infection has resulted in alteration of the digital flexor tendon sheath, the tendons and the tendon sheath should be thoroughly examined (Weaver, 1991; Kofler, 1994, 1996b, 2014). In both surgical techniques, namely resection of the distal sesamoid bone and DIJ resection, opening of the flexor tendon sheath is not always mandatory. However, because it is frequently infected, and septic tenosynovitis can be a postoperative complication, it is advisable to open the sheath, rinse it thoroughly with isotonic saline or with povidone-iodine solution and to administer antibiotics (Jeong, 1993), similarly for cases of digital amputation. Depending on the extent and severity of infection of tendons and tendon sheaths, a partial or complete removal is necessary, independent of the surgical technique used (Desrochers et al., 1995, 2008; Desrochers \& St-Jean, 1996; Bicalho et al., 2007).

If the infection of the deep flexor tendon has progressed more proximally, it can be resected with (Clemente, 1965; Köstlin and Nuss, 1988; Kofler, 1994) or without (Starke et al., 2007) incising the skin distal to the dewclaws or, together with the superficial flexor tendon, after incising the skin proximal to the dewclaws (Breuer, 1963; Westhues \& Breuer, 1964; Kofler, 1994; Nuss, 2004; Kofler \& Martinek, 2005; Bicalho et al., 2007).

\section{Dorsal approach}

The indications for resection of the DIJ using a dorsal approach include septic arthritis caused by a penetrating wound in the dorsal region. In addition to the dorsal approach, a second arthrotomy portal is created on the abaxial aspect. Cartilage, subchondral and necrotic bone are curetted and the joint should be lavaged via the two approaches. The portals stay open and can be used to lavage the joint postoperatively until the infection is under control (Desrochers and St-Jean, 1996, 2001). A Gerlach needle is used to make an axial or abaxial opening via the incision to allow placement of a drain through the joint. In contrast to the plantar/palmar approach, the distal sesamoid bone, deep digital flexor tendon, podotrochlear bursa and the tuberculum flexorium of P3 are not resected provided they are healthy (Desrochers et al., 1995, 2008; Desrochers \& St-Jean, 1996; Heppelmann et al., 2009a).

\section{Abaxial and axial approaches}

The indications for an abaxial or axial approach include septic arthritis of the DIJ caused by penetrating wounds or spread of infection, for example from white line disease or interdigital phlegmon (Desrochers \& St-Jean, 1996; Zulauf et al., 2001; Reinöhl-DeSouza \& Kofler, 2006). Using this approach the plantar/palmar, retroarticular structures may not be involved (Ferguson, 1997).

Starting at the primary lesion, the DIJ should be resected, and cartilage, subchondral and infected bone are removed with a curette, trephine or drill, which emerges in the dorsoaxial or axial region (Desrochers et al., 1995, 2008; Desrochers \& St-Jean, 1996; Zulauf et al., 2001) to allow joint lavage and placement of a fenestrated drain (Ferguson, 1997). The oblique drill holes are chosen to prevent injury to the healthy partner claw (Heppelmann et al., 2009a).
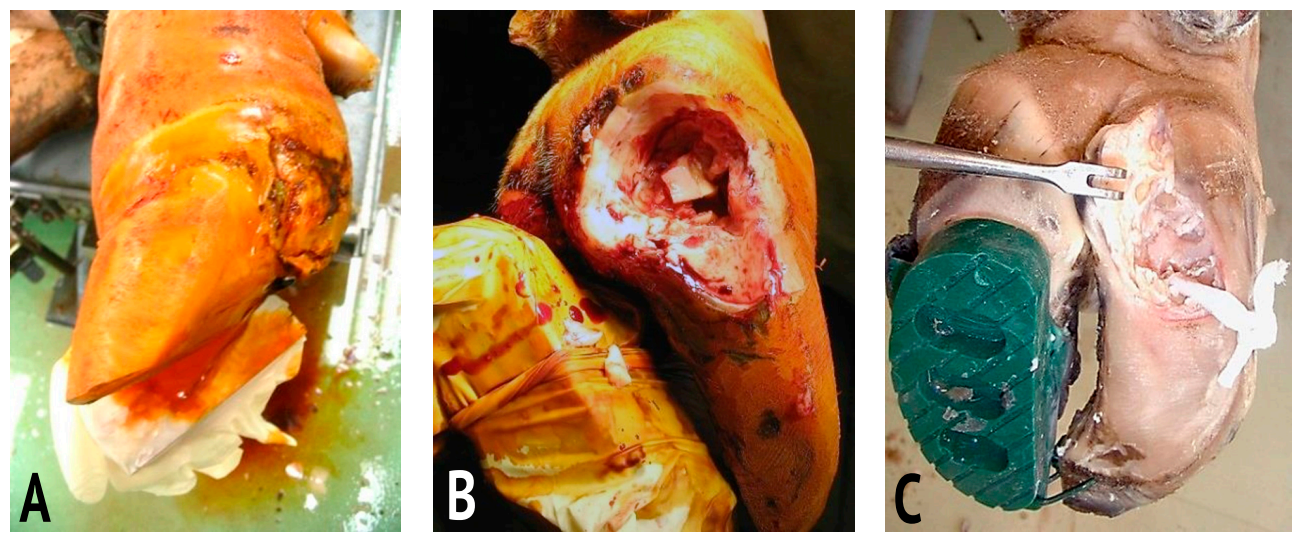
White line infection with deep digital sepsis prepared for resection of the DDFT at the insertion, the distal sesamoidal bone and DIJ resection (A); situation during removal of the DDFT at the insertion site (B), a part of the tendon is visible; and situation after removal of the DDFT (C).
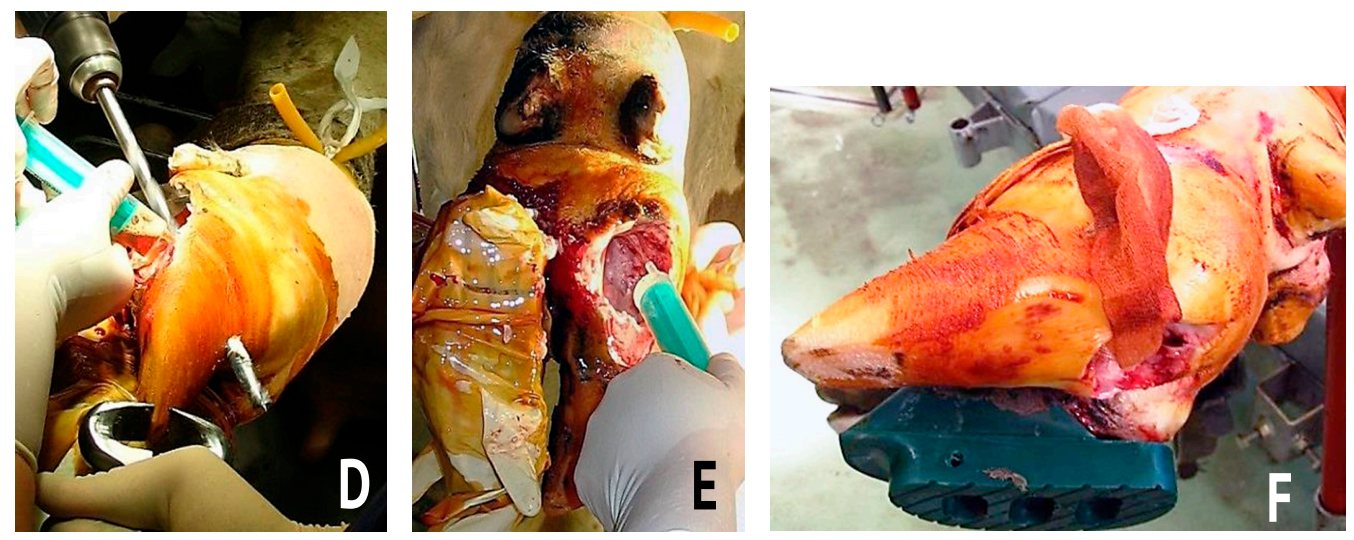

The same surgery showing drilling of a canal through the joint space of the DIJ from plantar to the dorsal wall at a level $1 \mathrm{~cm}$ distal of the coronary band (D), during drilling and after drilling the joint and the wound have to be lavaged with saline solution (E), and finally the wound and the canal is drained (F). In patients undergoing this surgery, a block at the partner claw has to be applied (F).
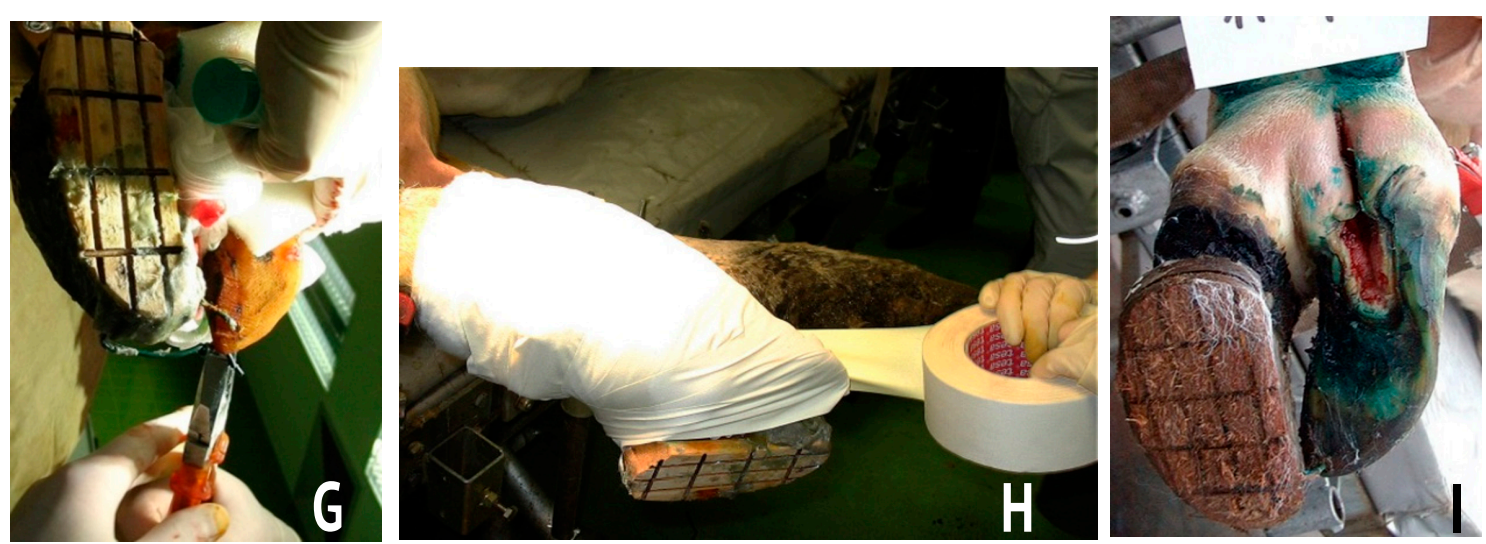

The same surgery showing here the application of the hyperextension-prophylaxis by restraining the treated claw in normal position (both claws showing a parallel dorsal wall contour) on the block on the partner claw using a wire (arrow; G); Correct application of the bandage rolls in direction of flexion of the treated digit (arrow) to support the hyperextension-prophylaxis $(\mathrm{H})$. (I): 18 days later: the surgical wound is more or less closed by granulation tissue, and the swelling is markedly decreased.

Independent of the approach chosen, the wound must be thoroughly lavaged with $0.9 \%$ isotonic saline solution with or without diluted povidoneiodine $(0.1 \%)$ during and after joint resection. Compared to digital amputation, DIJ resection does not allow complete exposure of the joint, which averts inspection of all the associated structures and constitutes a disadvantage. Although wide resection of abnormal tissues is likely to remove all infected tissue, this is not always the case. Within 7-14 days after surgery, deterioration of the patient's condition after a period of apparent improvement or no improvement may occur, if infected tissue (bone) has not been completely excised. This 
manifests as increased lameness and swelling of the affected region and recurrence of purulent discharge from the wound.

To resolve residual infection, more radical resection of the DIJ, or amputation of the claw, is necessary (Kofler \& Fessl, 1989; Heppelmann et al., 2009a).

\section{Digital amputation}

Digital amputation is the most commonly indicated procedure for disorders involving the phalanges distal of the fetlock joint, including severe purulent necrotising arthritis of the DIJ, the proximal interphalangeal joint (PIJ), severe osteolysis and osteomyelitis of P3 and P2, tumours of the claw region and other severe traumatic diseases of the claw (Westhues \& Breuer, 1964; Kofler \& Fessl, 1989; Pejsa et al., 1993; Desrochers \& St-Jean, 1996; Ferguson, 1997; Alton \& Kofler, 1998; Dirksen, 2002; Kofler et al., 2007; Starke et al., 2007; Pedersen, 2007; Desrochers et al., 2008; Heppelmann et al., 2009a).

Low amputation (removal at the mid-level of phalanx media: P2) is generally differentiated from high amputation (removal at the level of the distal aspect of the proximal phalanx: P1). The coronary band may or may not be preserved by any of the methods. In some techniques, skin flaps are prepared and sutured to cover the amputation stump, while other methods indicate that the wound should be left unclosed showing a second intention healing (Heppelmann et al., 2009a).

\section{Digital amputation through P2 (Ferguson method)}

For amputation through $\mathrm{P} 2$ without skin closure, a wire saw is used to cut through the middle of P2 (Kofler \& Fessl, 1989; Pejsa et al., 1993; Ferguson, 1997). To ensure correct positioning of the wire saw, a skin incision should be made approximately $1.0 \mathrm{~cm}$ proximal to the coronary band, beginning axially on the skin in the interdigital space and running dorsally and abaxially. This procedure is also possible in the sedated, standing animal bearing full weight on the limb after application of a regional intravenous anaesthesia (Ferguson,
1997). Still present purulent or necrotic debris on the amputation wound should be carefully removed after digital amputation (Kofler \& Fessl, 1989).

Disarticulation at the proximal interphalangeal joint (Amputation at the level of PIJ; Bouckaert method)

For disarticulation at the PIJ with closure of the wound, the skin is incised in an upside-down $\mathrm{T}$ pattern laterally: the longitudinal incision runs abaxially of the distal third of P1 to the coronary band, and the horizontal incision runs in the coronary band around the claw. The skin flaps are undermined and reflected forwards and backwards, respectively, and proximally, and the claw is removed by disarticulating the PIJ. All infected tissues are excised, the cartilage of the distal joint surface of P1 is thoroughly curetted and, if necessary, the interdigital fat pads are reduced to enable skin closure. The skin flaps are pulled over the stump and sutures closed (Bouckaert, 1964; Kofler \& Fessl, 1989).

\section{Digital amputation through the proximal phalanx}

This method can be used for treatment of purulent arthritis of the DIJ as well as for purulent arthritis of the PIJ with bone infection of the distal part of P1. The skin may or may not be closed after amputation. If closed (Zürich method), a dorsal skin incision is made from the proximal end of P1 to the coronary band. The incision is extended both into the interdigital space and abaxially. An analogous incision is made on the plantar/palmar aspect beginning distal of the dew claw and is extended distally to join the previous incision. The skin is undermined axially and abaxially. A wire saw is used to cut $\mathrm{P} 1$ obliquely $\left(45^{\circ}\right)$ from distal on the axial aspect to proximal on the abaxial aspect. The skin flaps are closed (Nuss, 2004).

If the skin is not closed (Ferguson method), a skin incision is made on the dorsal aspect parasagittally (as close as possible to the bone surfaces of the diseased digit approximately $4-6 \mathrm{~cm}$ in a proximal direction) and transecting the complete soft tissue to the plantar aspect axially, then a wire saw is used to amputate the digit in a $45^{\circ}$ angle to the digital axis, approximately $2 \mathrm{~cm}$ proximal to the PIJ 
(Weaver, 1991; Pejsa et al., 1993; Desrochers \& StJean, 1996; Ferguson, 1997). The advantage of the high amputation is that further excision of infected tissue is unnecessary (Weaver, 1991; Nuss, 2004).

There are pros and cons regarding the various reported amputation techniques. Selection of the method depends primarily on location, severity, and the extend of local inflammatory findings (e.g. severe phlegmon of the digit with skin fistulas or abscesses in combination with a purulent PIJ-arthritis or in contrast a fresh PIJ-arthritis with bone infection after trauma) and on the individual preferences and experience of the surgeon (Heppelmann et al., 2009).

In cases with only restricted inflammatory alterations and intact skin in the surgical site, Nuss (2004) recommended suturing the amputation wound in order to preserve the chance for first intention healing, with reduced pain for the treated animal and minimal post-surgical aftercare. In contrast, Kofler \& Fessl (1989), Weaver (1991) and Ferguson (1997) do not recommend skin closure after amputation because the stump cannot be inspected and it precludes timely recognition of signs of subcutaneous residual sepsis.

Irrespective, complete skin closure appears to be contraindicated in those amputation wounds with marked signs of inflammation in the remaining stump, which cannot be removed by further surgical excision. Therefore in such cases an amputation technique should be applied without skin closure or a drainage opening should be left to allow drainage of the inflammatory exudate (Kofler \& Fessl, 1989; Nuss, 2004; Kofler et al., 2007).

Generally, high digital amputation, either through the level of joint space of the PIJ or the distal aspect of P1 is recommended. In the remaining claw, low heels are commonly reported. Thus, in contrast to low digital amputation, high amputation will not only facilitate complete removal of all infected tissue, but will also avoid contact of the stump to the ground and therefore minimise postoperative pain if the heel of the partner claw is too low (Kofler \& Fessl, 1989; Nuss, 2004; Kofler et al., 2007; Heppelmann et al., 2009).
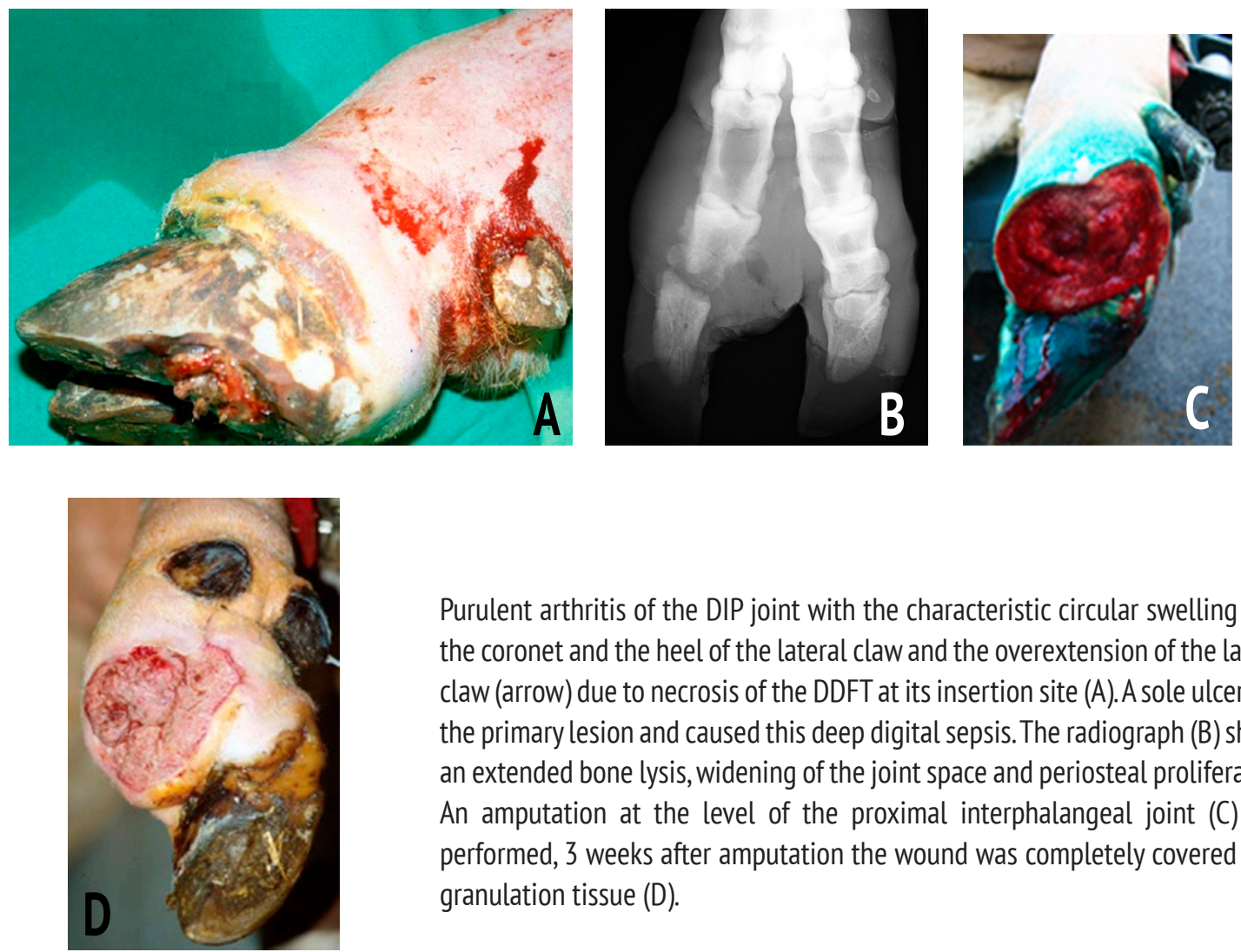

Purulent arthritis of the DIP joint with the characteristic circular swelling over the coronet and the heel of the lateral claw and the overextension of the lateral claw (arrow) due to necrosis of the DDFT at its insertion site (A).A sole ulcer was the primary lesion and caused this deep digital sepsis. The radiograph (B) shows an extended bone lysis, widening of the joint space and periosteal proliferation. An amputation at the level of the proximal interphalangeal joint $(C)$ was performed, 3 weeks after amputation the wound was completely covered with granulation tissue (D). 
Resection of the deep and superficial flexor tendons in cases of purulent tenosynovitis of the digital flexor tendon sheath

In cases of fibrino-purulent tenosynovitis of the digital flexor tendon sheath (DFTS) opening of the affected DFTS starting from the primary lesion - sole ulcer or penetrating skin wound - beginning with a skin incision at the mid of the bulbs of the heel to the mid of the dew claw. Then the incision is continued by surrounding the dew claw very closely axially and is continued for about $8-10 \mathrm{~cm}$ proximal of the dew claw of the affected digit. Then the fascia and the wall of the DFTS are incised over the complete extent of the flexor tendon sheath. Radical resection of the deep and superficial digital flexor tendon are recommended.
This is followed by removal of fibrin, necrotic tissue and flushing of the opened tendon sheath and open wound drainage (Breuer, 1963; Westhues \& Breuer, 1964; Kofler, 1994). During this procedure the surgeon should be careful to not open the adjoining digital flexor tendon sheath of the other digit.

The wound of the digital flexor tendon sheath is also drained and covered with Ligasano ${ }^{\circledR}$ foam dressing, it is not necessary to suture the tendon sheath wound (Breuer, 1963; Westhues \& Breuer, 1964; Kofler, 1994). A firm bandage using sterile dressing material is applied, and a hyperextension prophylaxis is applied. The first change of the bandage should be carried out 2 - 3 days after surgery, and the wound will be covered by granulation tissue within 2 - 3 weeks completely.
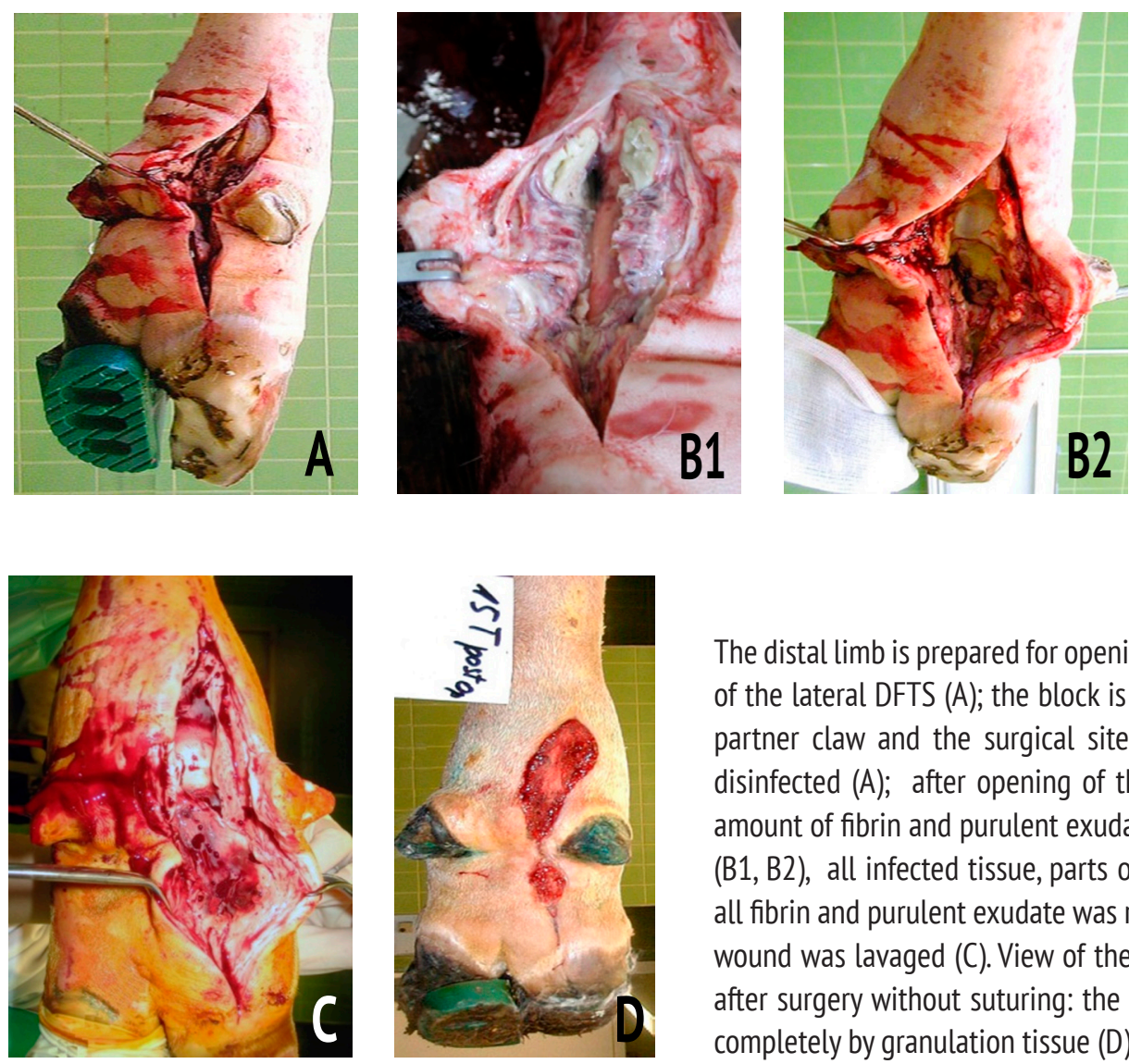

The distal limb is prepared for opening and resection of the lateral DFTS (A); the block is attached on the partner claw and the surgical site is cleaned and disinfected $(A)$; after opening of the DFTS a large amount of fibrin and purulent exudate was removed (B1, B2), all infected tissue, parts of the DFTS wall, all fibrin and purulent exudate was removed and the wound was lavaged (C). View of the wound 15 days after surgery without suturing: the wound is closed completely by granulation tissue (D). 


\section{Peri- and postoperative treatment}

\section{Wound care}

Large arteries identified at the amputation site should be ligated irrespective of the applied technique, even though there may be no bleeding detectable with the tourniquet in place (Bouckaert, 1964; Weaver, 1991). To avoid post-surgical bleeding after removal of the tourniquet, a firm pressure bandage is applied. If and how often bandages need to be changed depend on the local inflammatory findings and progress of healing. The first chance of the bandages is always indicated 2 or at least 3 days after surgery. The wound cavity is commonly covered with antibiotic or povidoneiodine ointments or powder and sterile gauze. There are various wound dressings reported in the literature, although the relative efficacy of each dressing has not been determined (Kofler \& Fessl, 1989; Nuss \& Weaver, 1991; Bicalho et al., 2006, 2007; Starke et al., 2007; Heppelmann et al., 2009a).

Polyurethane-soft-foam dressing (Ligasano $^{\circledR}$, Ligamed Medical Products, Germany or Momosan ${ }^{\circledR}$ Moltoplast GmbH, Innsbruck, Austria), a new wound dressing used in human medicine, may facilitate post-surgical healing (Kofler et al., 2004b; Kofler \& Martinek, 2005). It is used exclusively as a primary wound dressing after digital amputation or DIJ resection and in all other surgical procedures in bovine digits (Kofler et al., 2004b; Kofler \& Martinek, 2005). In contrast to sterile gauze swabs, no or only slight purulent exudate was observed when the wound was treated with this new dressing. The porous and alveolar structure of the $1 \mathrm{~cm}$ thick polyurethane soft foam sheet is intended to cause mechanical wound cleaning, and its suction effect shall ensure good drainage to prevent the accumulation of exudate and maceration of the wound surface (Kofler et al., 2004b).

Prevention of weight-bearing of the operated claw and Claw-hyperextension-prophylaxis

Following arthrotomy, joint lavage, distal sesamoid bone, amputation of the tip of the pedal bone, DIJ resection or resection of both flexor tendons, a wooden or rubber block is fixed to the opposite healthy claw to ensure that the operated claw does not contact the ground. If the deep digital flexor tendon is transected during surgery, a hyperextension-prophylaxis is commonly applied to prevent the operated toe from developing a permanent position of overextension (Köstlin \& Nuss, 1988; Jeong, 1993; Desrochers \& St-Jean, 1996; Ferguson, 1997; Kofler et al., 2007; Starke et al., 2007; Heppelmann et al., 2009a). The operated claw is attached to the opposite claw with a wire from a hole drilled into the horn wall at the tip of the claw to a second hole drilled into the block on the healthy claw. Alternatively, a metal bolt is attached to the wooden block and bent over the dorsal horn wall of the operated claw in order to keep the latter in a normal position. A bandage can also be used for fixation and it should run through a grove applied to the distal surface of the wooden block. When appling the bandage in such cases with removal of the DDFT the bandage roll have to be applied on the operated claw in a direction from dorsal over the tip of the claw to plantar to create a "flexion" of the digit and to avoid a permanent overextension (Köstlin \& Nuss, 1988; Jeong, 1993; Nuss, 2004; Starke et al., 2007; Heppelmann et al., 2009a). To achieve a good result, the attached block should remain for at least 6 - 8 weeks, and this manner of claw-hyperextension-prophylaxis has to be monitored/applied after each change of the bandage postoperatively.

\section{Systemic antibiosis}

Trueperella pyogenes, E. coli, Staphylococcus spp., Streptococcus spp., Fusobacterium necrophorum and Salmonella spp. have been isolated frequently from infected DIJ and deep digital sepsis in cattle (Kasari et al., 1987; Kofler \& Fessl, 1989; Trostle et al., 1996; Zulauf et al., 2001). Since septic arthritis of the DIJ is commonly accompanied by a varying degree of infection, most surgeons recommend parenteral administration of antibiotics for 3-17 days after DIJ resection (Köstlin \& Nuss, 1988; Baxter et al., 1991; Nuss \& Weaver, 1991; Desrochers et al., 1995, 2001; Heppelmann, 2004; Nuss, 2004; Bicalho et al., 2006, 2007) or amputation (Kofler \& Fessl, 1989; Desrochers et al., 1995; Desrochers \& StJean, 1996; Trent \& Redic-Kill, 1997; Bicalho et al., 
2006). Administration of antibiotics for 5-21 days after resolution of clinical signs is recommended in patients that have undergone joint lavage or arthrotomy (Baxter et al., 1991; Desrochers et al., 1995). Although not specifically tested, considering the results of these studies and from personal experience, it appears that a wide variety of antimicrobial drugs, such as penicillin, ampicillin, sulfonamides, fluoroquinolones or cephalosporins are effective (Kofler \& Fessl, 1989; Baxter et al., 1991; Kofler \& Stanek, 1998; Starke et al., 2007; Desrochers et al., 2008).

In spite of these reports, in my personal experience at the clinic parenteral antibiotics are not always indicated for postoperative treatment following digital amputation, providing that the amputation stump is free of signs of inflammation and the patient is kept in a clean and comfortable box (Heppelmann et al., 2009a).

\section{Anaesthesia and pain management}

Effective pain management is essential for all surgical procedures of the bovine digit and can be achieved in bovine practice too. It does not only allow the surgeon to operate safely, but also prevents sensitisation of the pain system and enhances convalescence by decreasing inflammation (Anderson \& Muir, 2005; Starke et al., 2008; Shearer et al., 2013). The application of an intravenous regional anaesthesia is mandatory and ideal for surgery of the bovine digit. In addition, the tourniquet necessary application of the intravenous regional anaesthesia has the beneficial effect of controlling bleeding during surgery. Intravenous regional anaesthesia has a rapid onset, is easier to perform and more reliable compared to nerve blocks and is therefore the method of choice for surgery of the distal bovine limb (Steiner et al., 1990; Stanek, 1994; Thurmon \& Ko, 1997; Klawuhn \& Staufenbiel, 2003). Regional intravenous anaesthesia also allows intravenous regional administration of a watersoluble antibiotic (Ceftiofur-sodium, oxytetracyclin) together with the local anaesthetic (Steiner et al., 1990; Stanek, 1994; Navarre et al., 1999).

Pre- and postoperative pain management is required for animal welfare reasons. It has been reported that it also improves feed intake and demeanour, which hastens healing and return to productivity (Thurmon \& Ko, 1997; Anderson \& Muir, 2005; Feist, 2004; Huxley \& Whay, 2006; Shearer et al., 2013). Non-steroidal antiinflammatory drugs (NSAIDs) are a good option because they have analgesic, anti-inflammatory and antipyretic properties (Barrett, 2004). Administration of NSAIDs for three days improves the general demeanour of cattle after surgery of the digit (Feist, 2004). Patients with long-standing claw disease suffer from chronic pain as well as acute pain caused by surgery. Chronic pain results in hypersensitivity and cannot be controlled with analgesics (Thurmon \& Ko, 1997; Feist, 2004; Shearer et al., 2013). In uncooperative or nervous cattle, an alpha-2 agonist, such as xylazine (0.05 - 0.1 $\mathrm{mg} / \mathrm{kg}$ intravenously (IV)) or detomidine $(10 \mathrm{mg} /$ $\mathrm{kg}$ IV), can be administered to relieve stress, keep the patient calm on the operating table and provide a mild analgesic effect (Thurmon \& Ko, 1997; Kofler \& Fessl, 1989; Starke et al., 2008; Heppelmann et al., 2009a; Rizk et al., 2012; Shearer et al., 2013).

After claw preserving surgical procedures, nonpharmacological methods of pain management after DIJ surgery include application of a wooden or plastic block on the healthy partner claw to prevent weight-bearing with the operated and painful claw. This procedure provides pain relief and supports healing because pressure on the surgical wound is avoided (Thurmon \& Ko, 1997; Van Amstel \& Shearer, 2006; Heppelmann et al., 2009a; Shearer et al., 2013). Since lame cattle frequently lie down, still in the postoperative period, a soft, clean and comfortable resting area must be provided. A box stall with firm, level, dry and non-skid flooring with easy access to a comfortable resting area with straw bedding is ideal (Heppelmann et al., 2009a).

\section{Outcome and postoperative survival after DIJ resection and digital amputation}

A postoperative mean survival time after resection of the distal interphalangeal joint and digital amputation of $13-20$ months with a range of 3 months to 6 years in individual cows was described in dairy cows (Funk, 1977; Ziffer, 1980; Köstlin \& Nuss, 1988; Kofler, 1991; Nuss \& Weaver, 
1991; Desrochers et al., 1995; Heppelmann, 2004). In contrast, in breeding bulls a higher mean survival time after digital amputation or DIJ resection of 27.2 and 21.2 months, respectively was reported (Kofler et al., 2007), which is distinctly longer than for cows. This may be attributable to more intensive long-term postoperative care and monitoring for lameness in breeding bulls than in dairy cows, and the less metabolic stress in bulls because the nonexisting milk production.

No advantage in longer postoperative life span is visible for a particular surgical technique. In a prospective clinical study Starke et al. (2007) compared the outcome after digital amputation and DIJ resection, and they did not find significant differences in the mean survival time of treated cows after claw-preserving surgery or amputation.

Bicalho et al. (2006) compared the life span of cows that had undergone digital amputation or DIJ resection with the life span of healthy untreated herd mates in two subsequent studies in the same herd. In both studies, healthy and treated cows did not differ with respect to age, production level, days in milk and parity. This comparison yielded a more realistic study method because culling factors other than foot surgery were considered.

The culling policy of herd owners can have considerable effects on the post-surgical outcome, so Barkema et al. (1994) reported that $33.9 \%$ of non-lame control cows, compared to $26.8 \%$ of lame cows, were slaughtered within the 3 year study period. The studies of Bicalho et al. (2006) in cows and that of Kofler et al. (2007) in heavy breeding bulls demonstrated that severe claw diseases, such as septic, purulent arthritis of the DIJ, do not necessarily lead to early culling if (with the owner's consent) cows and bulls, respectively, are adequately treated and thorough aftercare is provided.

It is clear that cows and bulls undergoing digital amputation or claw preserving surgery must be closely monitored for lameness and receive a regular claw care to avoid complications in the postoperative life (Heppelmann et al., 2009a). This is supported by the research of Bicalho et al. (2006) who found that total milk production was about 400-600 kg lower in cows during the first 60 days after amputation or DIJ resection, compared to healthy herd mates.

\section{Conclusion}

There is clear evidence that even under field conditions, cows with septic arthritis of the DIJ can have the same life expectancy as their unaffected herdmates when appropriate surgical treatment and aftercare is provided (Bicalho et al., 2006; Heppelmann, 2004; Heppelmann et al., 2009a). Reported evidence (Zulauf et al., 2001; Nuss, 2004) and personal experience suggests that rigorous case selection, aseptic preparation of the entire digit, precise surgical technique, meticulous curettage of infected bone and thorough lavage of the joint are the most critical factors for a successful outcome. In addition, a thorough examination of partner claws and claws of the contralateral limb for any disorders which maybe affect the ability to bear the extra weight after treatment of the affected claw is necessary (Kofler \& Fessl, 1989; Nuss and Weaver, 1991; Ferguson, 1997; Heppelmann et al., 2009a).

It is important to realise that the different surgical claw preserving and amputation techniques are not simply different alternatives that can be chosen randomly. The surgical options are dictated by the extent of inflammatory and necrotic alterations of the affected claw. While all necrotic material is generally removed by high amputation techniques, the risk that not all of the infected tissue is removed is substantially higher using claw preserving procedures (Köstlin \& Nuss, 1988; Nuss, 2004). Thus, for claw preserving methods, a more extensive pre-operative diagnostic workup, including arthrocentesis, radiography or ultrasonography, is usually required (Kofler \& Edinger, 1995; Stanek \& Kofler, 1995; Rohde et al., 2000; Starke et al., 2007, 2008; Kofler et al., 2014). A more definitive diagnosis permits the surgeon to more correctly decide whether a more invasive technique is indicated. With good diagnostic workup, careful case selection and adequate excision of infected tissues, amputation after unsuccessful joint resection is required in less than 3\% of cases (Köstlin \& Nuss, 1988; Bicalho et al., 2006; Starke et al., 2007). If imaging techniques are not available and clinical findings cannot be interpreted conclusively, it is better to opt for a more invasive procedure, such as amputation of the digit (Heppelmann et al., 2009a). 
The decision for surgical treatment of a cow is not only driven by medical, but also by economic considerations, such as age, value, milk production, stage of gestation and estimated replacement costs of the cow (Baxter et al., 1991; Ferguson, 1997). Profitability of a dairy operation depends, among other factors, on high production and longevity of the cows (Wangler et al., 2006). If a cow undergoes a mean of 2.4 lactations, profit may only arise if the cow produces at least $7500 \mathrm{~L}$ per year $(0.27$ Euro/L milk) (Wangler et al., 2006). Thus, the individual value as well as the long-term post-operative production potential of the cow must be considered.

Digital surgery allows the cow to return to further productive lactation, at least in statistical terms. Generally, digital amputation is the treatment of choice for older cows or cows close to the end of their productive life. Amputation is a rapid and simple procedure that can easily applied in practice and that ensures removal of all infected tissue and post-operative care is simple. Post-operative care for claw preserving methods is more expensive and more time-consuming, but provides more treatment options compared to amputation. Generally, a claw preserving surgery is recommended for heifers, for young valuable dairy cows and breeding bulls, provided the procedure is indicated medically and the owner is committed to investing some time and money (Baxter et al., 1991; Desrochers et al., 1995, 2008; Nuss, 2004; Kofler et al., 2007; Pedersen et al., 2007; Starke et al., 2007; Heppelmann et al., 2009a).

Furthermore, the degree of lameness decreases faster in cattle that have had digital amputation than those that have had DIJ resection (Starke et al., 2007). Usually a distinct improvement in lameness one day after amputation is observed and lameness continues to decrease rapidly until two weeks after surgery, which indicates that the pain resolved quicker (Starke et al., 2007; Mangweth et al., 2012). In contrast, using claw preserving techniques, the degree of lameness frequently becomes worse during the first days after surgery (Jeong, 1993; Nuss, 2004; Starke et al., 2007) and lameness scores often remain high for 2-3 weeks post-operatively (Nuss, 2004; Starke etal., 2007). This not only will distress the owner, but emphasises the requirement for more effective post-operative pain relieving strategies. Furthermore, accompanying measures, such as adequate wound dressing, local and systemic antibiotic treatment, short and longterm post-surgical aftercare, post-surgical housing conditions, and pain management protocols have substantial impact on the final outcome, well-being and productivity.

The long-term success of DIJ resection or digital amputation in cattle will also rely on close observation for new claw diseases in the partner claws or claws of the contralateral limb (Kofler and Fessl, 1989; Starke et al., 2007). Intensive daily (or weekly) monitoring for lameness and regular functional claw trimming every 3-4 months (Heppelmann et al., 2009a) should be an integral part of long-term care for all dairy cattle as part of good dairy farming practice.

\section{References}

Anderson DE, Muir WW. Pain Management in Ruminants. Vet Clin North Am Food Anim Pract. 2005;21(1):19-31.

Barkema HW, Westrik JD, Van Keulen KAS, Schukken $\mathrm{YH}$, Brand A. The effects of lameness on reproductive performance, milk production and culling in Dutch dairy farms. Prev Vet Med. 1994;20(4):249-59.

Barker ZE, Amory JR, Wright JL, Mason SA, Blowey RW, Green LE. Risk factors for increased rates of sole ulcers, white line disease, and digital dermatitis in dairy cattle from twenty-seven farms in England and Wales. J Dairy Sci. 2009;92(5):1971-8.

Barrett DC. Non-steroidal anti-inflammatory drugs in cattle - should we use them more? Cattle Pract. 2004;12:69-73.

Baxter GM, Broome TA, Lakritz JL, Parks AH, Wallace CE. Alternatives to digit amputation in cattle. Compend Contin Educ Vet. 1991;13:1022-35.

Bergsten C, Greenough PR, Weaver AD. Infectious diseases of the digits. Lameness in Cattle. Vol. 3. Philadelphia: WB Saunders; 1997. p. 89-100.

Bicalho RC, Cheong SH, Warnick LD, Nydam DV, Guard CL. The effect of digit amputation or arthodesis surgery on culling and milk production in Holstein Dairy cows. J Dairy Sci. 2006;89(7):2596-602. 
Bicalho RC, Cheong SH, Guard CL. Field technique for the resection of the DIJ and proximal resection of deep digital flexor tendon in cows. Vet Rec. 2007;160:435-9.

Blikslager AT, Baines SJ, Bowman KF. Excision of the distal sesamoid bone for treatment of infection of the digit in a heifer. J Am Vet Med Assoc. 1992;201(12):1905-6.

Booth CJ, Warnick LD, Gröhn YT, Maizon DO, Guard CL, Janssen D. J Dairy Sci. 2004;87(12):4115-22.

Bouckaert JV, 1964. Lameness in cattle. Nord Vet Med. 1964;16(Suppl. 1):225-40.

Breuer D. NeueOperationsverfahrenbeimKlauengeschwür der Rinder. Tierarztl Umsch. 1963;18:646-53.

Bruijnis MRN, Hogeveen H, Stassen EN. J Dairy Sci. 2010 Jun;93(6):2419-32.

Cha E, Hertl JA, Bar D, Gröhn YT. The cost of different types of lameness in dairy cows calculated by dynamic programming. Prev Vet Med. 2010;97(1):1-8.

Clarkson MJ, Downham DY, Faull WB, Hughes JW, Manson FJ, Merrit JB, et al. Vet Rec. 1996;138(23):563-7.

Cook NB, Nordlund KV. The influence of environment on dairy cow behaviour, claw health \& herd dynamics. Vet J. 2009;179(3):360-9.

Desrochers A, St-Jean G, Anderson DE. Use of facilitated ankylosis in the treatment of septic arthritis of the distal interphalangeal joint in cattle: 12 cases (1987-1992). J Am Vet Med Assoc. 1995;206(12):1923-7.

Desrochers A, St-Jean G. Surgical management of digit disorders in cattle. Vet Clin North Am Food Anim Pract. 1996;12(1):277-98.

Desrochers A, Anderson DE, St-Jean G. Surgical diseases and techniques of the digit. Vet Clin North Am Food Anim Pract. 2008;24(3):535-50, vii.

Döpfer D, Holzhauer M, Van Boven M. The dynamics of digital dermatitis in populations of dairy cattle: modelbased estimates of transition rates and implications for control. Vet J. 2012;193(3):648-53.
EFSA. Scientific opinion on welfare of dairy cows in relation to leg and locomotion problems based on a risk assessment with special reference to the impact of housing, feeding, management and genetic selection. EFSA Journal. 2009;1142:1-57.

Enting H, Kooij D, Dijkhuizen AA, Huirne RBM, NoordhuizenStassen EN. Economic losses due to clinical lameness in dairy cattle. Livest Prod Sci. 1997;49(3):259-67.

FeistM.UntersuchungenzumSchmerzausdrucksverhalten bei Kühen nach Klauenoperationen [dissertation]. Munich: Ludwig-Maximilian University of Munich; 2004.

Ferguson JG. Surgery of the distal limb. In: Greenough, PR, Weaver AD (eds): Lameness in cattle. 3rd ed. Philadelphia: W.B. Saunders; 1997. p. 248-61.

Funk KA. Spätergebnisse nach Zehen- und Klauenamputation beim Rind. Berl Münch Tierärztl Wschr. 1977;90: 152-6.

Green LE, Hedges VJ, Schukken YH, Blowey RW, Packington AJ. The impact of clinical lameness on the milk yield of dairy cows. J Dairy Sci. 2002;85(9):2250-6.

Greenough PR, Ferguson JG. Alternatives to amputation. Vet Clin North Am Food Anim Pract. 1985;1(1):195-203.

Heppelmann M, Kofler J, Meyer H, Rehage J, Starke A. Advances in surgical treatment of septic arthritis of the distal interphalangeal joint in cattle - a review. Vet J. 2009a;182(2):162-75.

Heppelmann M, Rehage J, Kofler J, Starke A. Ultrasonographic diagnosis of the septic arthritis of the distal interphalangeal joint in cattle. Vet J. 2009b;179(3):407-16.

Heppelmann M. Eitrige Klauengelenksentzündung beim Rind: Vergleich des Heilungsverlaufes nach Klauengelenksresektion mit plantarem Zugang und nach hoher Klauenamputation [dissertation]. Hanover: University of Veterinary Medicine Hanover; 2004.

Hernandez J, Shearer JK, Webb DW. Effect of lameness on the calving-to-conception interval in dairy cows. J Am Vet Med Assoc. 2001;218(10):1611-4. 
Hernandez J, Shearer JK, Webb DW. Effect of lameness on milk yield in dairy cows. J Am Vet Med Assoc. 2002;220(5):640-4.

Huxley JN, Whay HR. Current attitudes of cattle practitioners to pain and the use of analgetics in cattle. Vet Rec. 2006;159:662-8.

Jeong S. Vergleichende Untersuchungen zum Heilungsverlauf nach Klauensesambeinresektion ohne und mit Teilresektion des Tuberculum flexorium des Klauenbeins sowie des plantaren bzw. palmaren Anteiles des distalen Gelenksfläche des Kronbeines (mittels Fräse) beim Rind [dissertation]. Hanover: University of Veterinary Medicine Hanover; 1993.

Kasari TR, Marquis H Scanlan CM. Septic arthritis and osteomyelitis in a bovine digit: a mixed infection of Actinomyces pyogenes and Fusobacterium necrophorum. Cornell Vet. 1988;78(3):215-9.

Klawuhn D, Staufenbiel R. Zur Technik der intravenösen Regionalanästhesie an der Rindergliedmaße. Prakt Tierarzt. 2003;84:38-45.

Kofler J, Fessl L. Comparison of the methods of amputation through phalanx media versus exarticulation in the proximal interphalangeal joint in cattle. Wien Tierarztl Monatsschr. 1989;76:224-30.

Kofler J. Life expectancy of cattle after amputation or exarticulation of a digit. Wien Tierarztl Monatsschr. 1991;78:84-90.

Kofler J. Sonography as a new diagnostic tool for septic tenosynovitis of the digital flexor tendon sheath in cattle- therapy and long term follow-up. Dtsch Tierarztl Wochenschr. 1994;101:215-22.

Kofler J Edinger H. Diagnostic ultrasound imaging of the soft tissues in distal bovine limb. Vet Radiol Ultrasound. 1995;36(3):246-52.

Kofler J. Arthrosonography: The use of diagnostic ultrasound in septic and traumatic arthritis in cattle - a retrospective study of 25 patients. Br Vet J. 1996a;152(6):683-98.
Kofler J. Sonographic imaging of pathology of digital flexor tendon sheath in cattle. Vet Rec. 1996b;139:36-41.

Kofler J, Stanek CH. Treatment of complicated septic disorders of the bovine digit, using a combination of surgical therapy and application of Sodium-Ceftiofur. Tierarztl Prax. 1998;26(G):314-7.

Kofler J. Clinical study of toe ulcer and necrosis of the apex of the distal phalanx in 53 cattle. Vet J. 1999;157(2):139-47.

Kofler J, Martinek B, Reinöhl-DeSouza C. Treatment of infected wounds and abscesses in bovine limbs with Ligasano®-Polyurethane-softfoamdressingmaterial.Berl Munch Tierarztl Wochenschr. 2004;117(9-10):428-38.

Kofler J, Martinek B. New surgical approach to the plantar fetlock joint through the digital flexor tendon sheath wall and suspensory ligament apparatus in cases of concurrent septic synovitis in two cattle. Vet J. 2005;169(3):370-5.

Kofler J, Feist M, Starke A, Nuss K. Resection of the distal / proximal interphalangeal joint and digit amputation in 21 breeding bulls - indications, clinical findings and long-term outcome. Berl Munch Tierarztl Wochenschr. 2007;120(3-4):156-64.

Kofler J. Ultrasonography as a Diagnostic Aid in Bovine Musculoskeletal Disorders. Vet Clin North Am Food Anim Pract. 2009;25(3):687-731.

Kofler J. Orthopädischer Untersuchungsgang. In: Baumgartner W (Ed). Klinische Propädeutik der Haus- und Heimtiere. 8th ed. Berlin-Wien: Parey; 2014. p. 216-81.

Kofler J, Geissbühler U, Steiner A. Diagnostic imaging in bovine orthopedics. Vet Clin North Am Food Anim Pract. 2014;30(1):11-53, v.

Kofler J, Glonegger-Reichert J, Dietrich J, Sykora S, Tichy A, Brandt S. A simple surgical treatment for Digital Dermatitis-associated white line lesions and sole ulcers. Vet J. 2015;204(2):229-31.

Kofler J. Pathogenesis and treatment of toe lesions in cattle (including non-healing toe lesions). Vet Clin North Am Food Anim Pract. 2017;33(2):301-28. 
Kofler J, Osova A, Altenbrunner-Martinek B, Burgstaller J. Apical pedal bone necrosis (toe necrosis) in 30 cattle - retrospective evaluation of the treatment methods and outcome. Wien Tierarztl Monatsschr. 2017;104:131-42.

Köstlin RG, Nuss K. Behandlung der eitrigen KlauengelenkentzündungbeimRind durchGelenkresektion - Ergebnisse. Tierarztl Prax. 1988;16:123-31.

Mangweth G, Peham C, Altenhofer C, Weber A, Gasser C, Schramel P, et al. Lameness detection in cows by accelerometric measurement of motion at walk. Berl Munch Tierarztl Wochenschr. 2012;125:386-96.

Meier C. Vorgehensweise bei eitriger Gelenksentzündung des erwachsenen Rindes und klinische Erfahrungen mit der Spülbehandlung. Prakt Tierarzt. 1997;78:893-906.

Morck DW, Olson ME, Louie TJ, Koppe A, Quinn B. Comparison of ceftiofur sodium and oxytetracycline for treatment of acute interdigital phlegmon (foot rot) in feedlot cattle. J Am Vet Med Assoc. 1998;212(2):254-7.

Navarre CB, Zhang L, Sunkara G, Duran SH, Kompella UB. Ceftiofur distribution in plasma and joint fluid following regional limb injection in cattle. J Vet Pharmacol Ther. 1999;22(1):13-9.

Nocek JE. Bovine acidosis: implications on laminitis. J Dairy Sci. 1997;80(5):1005-28.

Nuss K. Operationen an Klaue und Zehe. In: Fiedler A, Maierl J, Nuss K. Erkrankungen der Klauen und Zehen des Rindes. 1st ed. Stuttgart: Verlag Schattauer; 2004. p. 130-59.

Nuss K, Weaver MP. Resection of the distal interphalangeal joint in cattle: an alternative to amputation. Vet Rec. 1991;128(23):540-3.

O'Callaghan KA. Lameness and associated pain in cattle - challenging traditional perceptions. In Pract. 2002;24:212-9.

Olechnowicz J, Jaskowski JM. Incidence and prevalence of lameness and their relationship to milk yield in highyielding cows. Medycyna Wet. 2010;66(12):818-21.
Olechnowicz J, Jaskowski JM. Reasons for culling, culling due to lameness, and economic losses in dairy cows. Medycyna Wet 2011;67(9):618-21.

Pedersen SL. Milk production and survival following digit amputation in dairy cattle. Cattle Pract. 2007;15(3):256-60.

Pejsa TG, St Jean G, Hoffsis GF, Musser JM. Digitamputation in cattle: 85 cases (1971-1990). J Am Vet Med Assoc. 1993;202(6):981-4.

Reinöhl-DeSouza C, Kofler J. Interdigital necrobacillosis (interdigital phlegmon) in 66 cows - part II: treatment and outcome. Tierarztl Prax. 2006;34(G):80-5.

Rhode C, Anderson DE, Desrochers A, St-Jean G, Hull BL, Rings DM. Synovial fluid analysis in cattle: a review of 130 cases. Vet Surg. 2000;29(4):341-6.

Rizk A, Herdtweck S, Meyer H, Offinger J, Zaghloul A, Rehage J. Effects of xylazine hydrochloride on hormonal, metabolic, and cardiorespiratory stress responses to lateral recumbency and claw trimming in dairy cows. J Am Vet Med Assoc. 2012;240(10):1223-30.

Rouha-Mülleder C, Iben C, Wagner E, Laaha G, Troxler J, Waiblinger S. Relative importance of factors influencing the prevalence of lameness in Austrian cubicle loose housed dairy cows. Prev Vet Med. 2009;92(1-2):123-33.

Sárová R, Stéhulová I, Kratinová P, Firla P, Śpinka M. Farm managers 12 underestimate lameness prevalence in Czech dairy herds. Anim Welf. 2011;20:201-4.

Shearer JK, Stock ML, Van Amstel SR, Coetzee JF. Assessment and management of pain associated with lameness in cattle. Vet Clin North Am Food Anim Pract. 2013;29(1):135-56.

Stanek C. Basis of intravenous regional antibiosis in digital surgery in cattle. Isr J Vet Med. 1994;49(2):53-8.

Stanek C, Kofler J. On the classification of radiological changes in septic arthritis of the DIJ in cattle: comparison of two scoring systems. Wien Tierarztl Monatsschr. 1995;82:390-6. 
Starke A, Heppelmann M, Beyerbach M, Rehage J. Septic arthritis of the DIJ in cattle: comparison of joint resection by solar approach and digital amputation. Vet Surg. 2007;36(4):350-9.

Starke A, Heppelmann M, Meyer H, Rehage J. Diagnosis \& therapy of septic arthritis in cattle. Cattle Pract. 2008;16:36-43.

Steiner A, Ossent P, Mathis GA. Die intravenöse Stauungsanästhesie/-antibiose beim Rind - Indikationen, Technik, Komplikationen. Schweiz Arch Tierheilkd. 1990;132:227-37.

Thurmon JC, Ko JCH. Anesthesia and chemical restraint. In: Greenough PR, Weaver AD (eds.). In: Lameness in cattle. 3rd ed. Philadelphia: W.B. Saunders; 1997. p. 41-55.

Trent AM, Redic-Kill A. Clinical pharmacology. In: Greenough PR, Weaver AD (eds.). In: Lameness in cattle. 3rd ed. Philadelphia: W.B. Saunders; 1997. p. 56-70.

Trostle SS, Hendrickson DA, Stone WC, Klohnen AA. Use of antimicrobial-impregnated polymethyl methacrylate beads for treatment of chronic, refractory septic arthritis and osteomyelitis of the digit in a bull. J Am Vet Med Assoc. 1996;208:404-7.

Van Amstel SR, Shearer JK. Review of pododermatitis circumscripta (ulceration of the sole) in dairy cows. J Vet Intern Med. 2006;20(4):805-11.

Wangler A, Harms J, Rudolphi B, Blum E, Böttcher I, Kaven D. Verlängerung der Nutzungsdauer der Milchkühe durch eine gute Tiergesundheit bei gleichzeitig hoher Lebensleistung zur Erhöhung der Effizienz des Tiereinsatzes. Forschungsbericht (Nr. 2/22), Landesforschungsanstalt für Landwirtschaft und Fischerei Mecklenburg-Vorpommern, Institut für Tierproduktion. 2006 [cited 2014 Sep 28]. Available from: https://tinyurl.com/y9ny8tnz.

Warnick LD, Janssen D, Guard CL, Gröhn YT. The effect of lameness on milk production in dairy cows. J Dairy Sci. 2001;84(9):1988-97.

Weaver AD. Performing amputation of the bovine digit. Vet Med US. 1991;86:1230-3.
Westhues M, Breuer D. Klauengelenkresektion und Sehnenresektion beim Klauengeschwür des Rindes. Nord Vet Med. 1964;16(Suppl. 1):335-43.

Whitaker DA, Kelly JM, Smith S. Disposal and disease rates in 340 British dairy herds. Vet Rec. 2000;146(13):363-7.

Ziffer A. Untersuchungen über Verbleib und Milchleistung von Rindern nach Klauenamputation [dissertation]. Hanover: University of Veterinary Medicine Hanover; 1980.

Zulauf M, Jordan P, Steiner A. Fenestration of the abaxial hoof wall and implantation of gentamicin-impregnated collagen sponges for the treatment of septic arthritis of the distal interphalangeal joint in cattle. Vet Rec. 2001;149(17):516-8. 